\title{
About This Book
}

Walking Harlem traces the musical, literary, visual arts, dance, and socio-political developments in Harlem from around I9I9 to the present with a focus on the I920s-1930s Harlem Renaissance. The book draws from numerous sources including historical and out-of-print texts, newspapers, record liner notes, and film to focus on the cultural, arts, and political developments of African Americans in Harlem, and it links this information to five self-guided walking tours. The author's background as an ethnomusicologist is evident in a focus on music venues that have often been overlooked in previous researches.

Tours are based on proximity of sites to one another along each tour route; however, key themes may be identified in each tour. Tour I includes the Schomburg Center, Striver's Row, key literati locales, Abyssinian Baptist and Mother AME (African Methodist Episcopal) Zion Churches, the (original) Cotton Club, and the Savoy Ballroom. Tour 2 also begins at the Schomburg Center and features community art murals funded by the Works Progress Administration and small and large music entertainment venues and speakeasies. Tour 3 includes 125 th Street, 
the Apollo Theater, the Mount Morris District, Minton's Playhouse jazz club, the former homes of Langston Hughes and Maya Angelou, and the original site for Temple No. 7 (Malcolm X's religious and spiritual home from the midI950s to the mid-I960s). Tour 4 covers the City College of New York and the (Alexander) Hamilton Heights district. Tour 5 covers the neighborhood of Sugar Hill's apartment buildings and nightclubs and pre-Harlem Renaissance sites (Morris-Jumel Mansion and Jumel Terrace). The tour ends at the Malcolm X and Dr. Betty Shabazz Memorial and Educational Center (the former Audubon Ballroom) in Washington Heights. The estimated times per tour are included at the beginning of each tour, and recommended restaurants and eateries are included in each tour for walkers to stop and take a break along the tour routes if desired.

This tour guidebook and its accompanying maps provide a concise history with background on the most significant developments of the Harlem Renaissance era and beyond with the places and people associated with them. Those who are interested in reading a more in-depth background on social developments or important Harlem personalities can refer to part 2 of the book, enabling you to greater familiarize yourself with the social-politicalcultural history of Harlem.

In addition to reading and following the tours in this book, I encourage you to expand on your knowledge and appreciation of Harlem's vast and rich culture on your own 
by revisiting sites that remain in operation today and those that have sprung up since the Renaissance era but reflect back on Harlem's rich past as well as celebrate its present and future. 


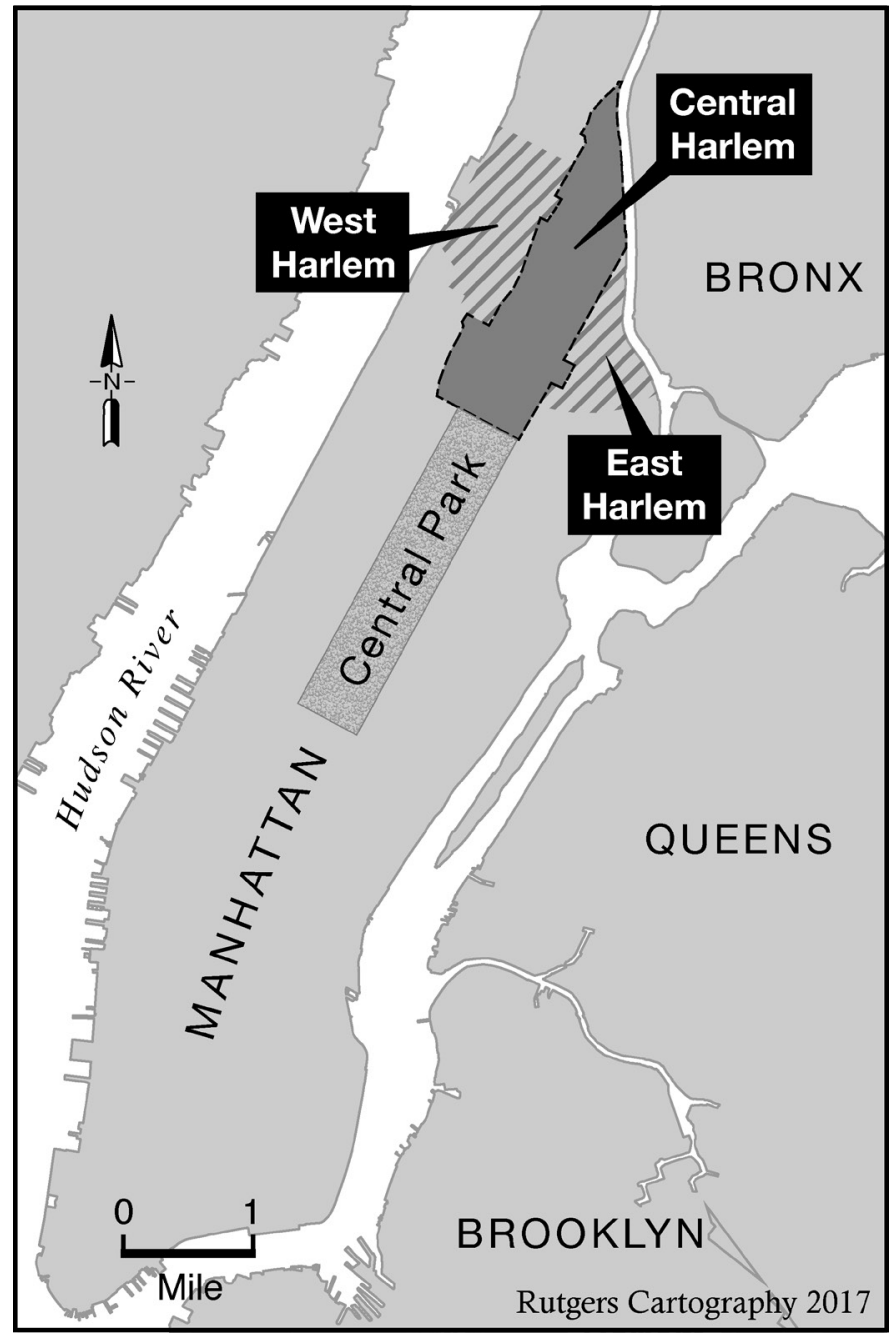




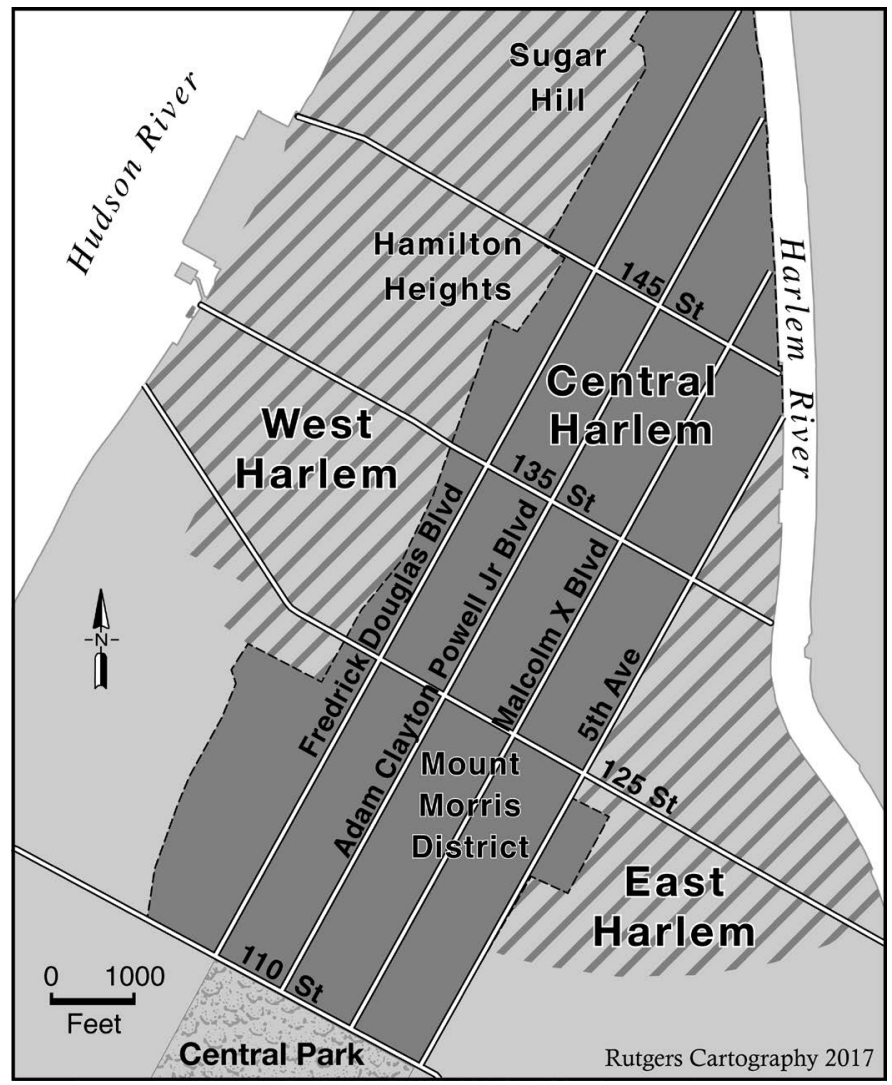

Harlem is roughly located north of IIoth Street (Central Park North), south and west of the Harlem River, and east of the Hudson River. Subsections of Harlem include Spanish Harlem, to the east of Fifth Avenue, spiraling outward from in6th Street, and West Harlem, including Hamilton Heights and Sugar Hill. 



\section{Walking Harlem}


